\title{
STABILIZATION AND SPECIFICATION OF CHARACTERISTIC VALUE OF GEOTECHNICAL PARAMETERS
}

\author{
IVAN VANÍČEK
}

\begin{abstract}
Czech Technical University in Prague, Faculty of Civil Engineering, Thákurova 7, Prague 6, Czech Republic correspondence: ivan.vanicek@cvut.cz
\end{abstract}

\begin{abstract}
Soil stabilization, process, by which the soil properties are improved, is getting growing attention during last periods. Paper is focused on application for earth structures. Methods of soil stabilization together with their applicability for different soils are discussed firstly. The sensitivity of the process of the cautious estimation of the characteristic values of geotechnical parameters which are subsequently used for the design, is shown on the base of the logical scheme of the geotechnical design report for earth structures. Finally the need of the laboratory tests for the closer specification of the soil stabilization technology and also for the determination of the geotechnical data are discussed.
\end{abstract}

KEYwORDS: Stabilization, Earth structure, Eurocode 7, characteristic value.

\section{INTRODUCTION}

Soil stabilization is one of the techniques of soil improvement. Together with soil reinforcement it is the most applied techniques. Soil improvement methods can be divided with respect to the characteristic values specification into two basic subgroups [1]:

- Diffusive soil improvement;

- Discrete soil improvement.

In the first case, typical for soil stabilization, the design counts with new properties for geological environment in general, better speaking for individual quasi-homogeneous layers of the environment. In the second case soil properties remain the same (on the previous values), as well the parameters of the reinforcing element (most often geosynthetics). The behaviour of the composite therefore depends on the interaction of these two basic materials and limit states of failures should be determined also for this reinforcing element. For earth structures the improvement of individual soil layers of fill or surface of ground (subsoil) has dominant application role. It is typical for earth structures of transport engineering including airports. However it is connected also with subsoil improvement of large halls, especially when they are founded partly in cut and partly on fill. Soil stabilization, mixing soil particles with different additives, can be realized either on site or in mixing centre situated of-site with subsequent transport on the place of application. Additives are different, either according to the soil type or with respect of certain demands. The following additives can be applied [2]:

- Lime, cement, plaster;

- Industrial by products as fly ash, energy-gypsum, slag (cinder) [3];

- Additional soil - mechanically stabilized soil;

- Several chemical additives (resins, bitumen).
The paper is for the simplicity focused on the first possibility, on the application of lime or cement, whereas cement is typical for coarse soil and lime for fine grained soils. The recommendation in this direction are often connected with index plasticity. For cement application, the higher strength is reached, however the strength is rising up relatively slowly. The final result is more typical for road base or subbase or for layers just below floor (e.g. for above mentioned halls), where higher strength is typically demanded. Subsequently more attention is focused on lime application, which is more suitable for fine soils and where quicker effect of application is needed.

\section{Lime STABILIZATION}

Quick lime is preferred for soil stabilization as it hydrates with water and calcium hydroxide develops. This reaction is exothermic. Heat is created as the result of quick lime reaction with wet soil having quick impact on soil compaction which is after that for dryer soil better. Therefore generally two impacts are distinguished, short term (having positive impact on soil compaction) and long term (having positive impact on strength increase). While short term effect occurs for any quick lime application, long term effect need a certain percentage of quick lime. Broadly speaking this boundary is close to $2 \%$ of added lime to dry soil. Particle flocculation starts for higher content of lime, changing grain size distribution curve with lower content of fine particles. Soil creates clods and change the structure. Therefore for fine grain soils the stabilization process with lime leads to:

- Better soil workability;

- Strength increase.

From this point of view the long term effect is more important for increase of characteristic values of geotechnical parameters, however requires higher lime 
content, usually in the range of 2 to $6 \%$. Stabilization effect connected with long term effect is therefore connected with reaction of lime with clay particles, subsequently leading to:

- Growth in strength and the subsoil bearing capacity in general - due to the creation of cementing bonds resulting from soil-lime pozzolanic reaction, which, however, develop in time and therefore strength tests are performed with a time lag of mostly 28 days;

- Reduction in the susceptibility to swelling and shrinkage;

- Reduction in moisture content is caused both by absorption, extraction of moisture from the surrounding soil after the lime type is changed into slake lime, and by hydration heat as was mentioned above.

At the same time, however, the new reaction of lime with clay minerals leads to a change in plasticity thus affecting another factor relevant for workability.

- Two additional notes are needed [4];

- For higher content of quick lime (above 4-6\%) there is no another reduction of plasticity;

- For the development of cementing bonds clay particles are needed, at least $10 \%$.

\section{TeChnology EFFECT}

The application of lime stabilization on site prevails at the present days. After areal spreading of the demanded content of lime the soil and lime are mixed with the help of cutter or another machineries to the required depth. Such modified layer is levelled by grader or bulldozer and subsequently compacted by roller. A great attention is devoted to the moisture content at the time of compaction, to guarantee that soil after compaction will not have more than 5 percent of air in pores.

Therefore some specialists devote a great attention to the mellowing - maturing, to the time between soil and lime mixing and final compaction. Therefore after mixing only light compaction is recommended and after about 24 to 72 hours, followed by second mixing supplemented by additional increase of water the final compaction is applied. It is consistent that this recommendation has some limits, as for example for improvement of railway tract subsoil during rail heave [5].

From this technology point of view the application of lime stabilization is not recommended during late autumn, as stabilized soil can freeze. For such case addition of cement is recommended after short delay after lime. Nevertheless this recommendation has general character, as lime can prepare soil for cement application. This effect can be reached by some special mixed additives, e.g. for the Czech Republic it is Dorosol, which contains a certain percentage of lime and the rest are hydraulic ingredients. In this case a special attention is devoted to dusting lowering.

\section{LOGICAL SCHEME OF THE EARTH STRUCTURE DESIGN}

Contemporary version of the Eurocode 7 Geotechnical design contains four important steps of the geotechnical structure design and performance as specification of geological model, geotechnical model, calculation model and ending with structure realization, performance connected with structure control. These four phases can be used for the specification of the risk with which the design and performance is connected, first of all from the point of view of uncertainties and indeterminateness. For earth structures this scheme is presented in Fig. 1 in the form of the Geotechnical design report - GDR.

Geological model should be specified not only for the ground but also for the borrow pit, from which fill will be constructed. Geotechnical investigation report or Ground investigation report - GIR - includes not only geological model but also results of the laboratory and field tests of the ground and theirs presentation in the form of measured or derived geotechnical parameters. From the borrow pit technological samples are taken and subsequently tested in the laboratory. Firstly it is compaction test - most often Proctor standard test.

Range of the geotechnical investigation as well the range of performed tests is connected with risk, with which the design and performance is connected. Eurocode 7 recommends three degrees for this specification - with the help of so called Geotechnical categories (GC), when into:

- 1 GC belongs simple structures in modest geological and geotechnical conditions. These structures are designed with the help of up to day experiences calculation of limit states is not needed. Generally into first GC belongs fills with high up to $3 \mathrm{~m}$ with good ground conditions. However this is not the case for the ground of fill which need improvement - soil stabilization.

- 3 GC belongs very demanding structures, or structures with complicated ground - from the geological and geotechnical point of view or structures connected with extreme risk for surrounding environment in the case of failure.

- 2 GC belongs all other structures.

For the structures falling into $3 \mathrm{GC}$ it is necessary always determine mechanical-physical properties - either for ground or for fill. For material of fill the test are performed on samples compacted in laboratory and for which moisture content and dry density are falling into the accepted (recommended) range. The same procedure is recommended for structure which belongs to the second GC, however with one exception. In the case of $2 \mathrm{GC}$ connected with lower risk the mechanical-physical properties can be selected from 


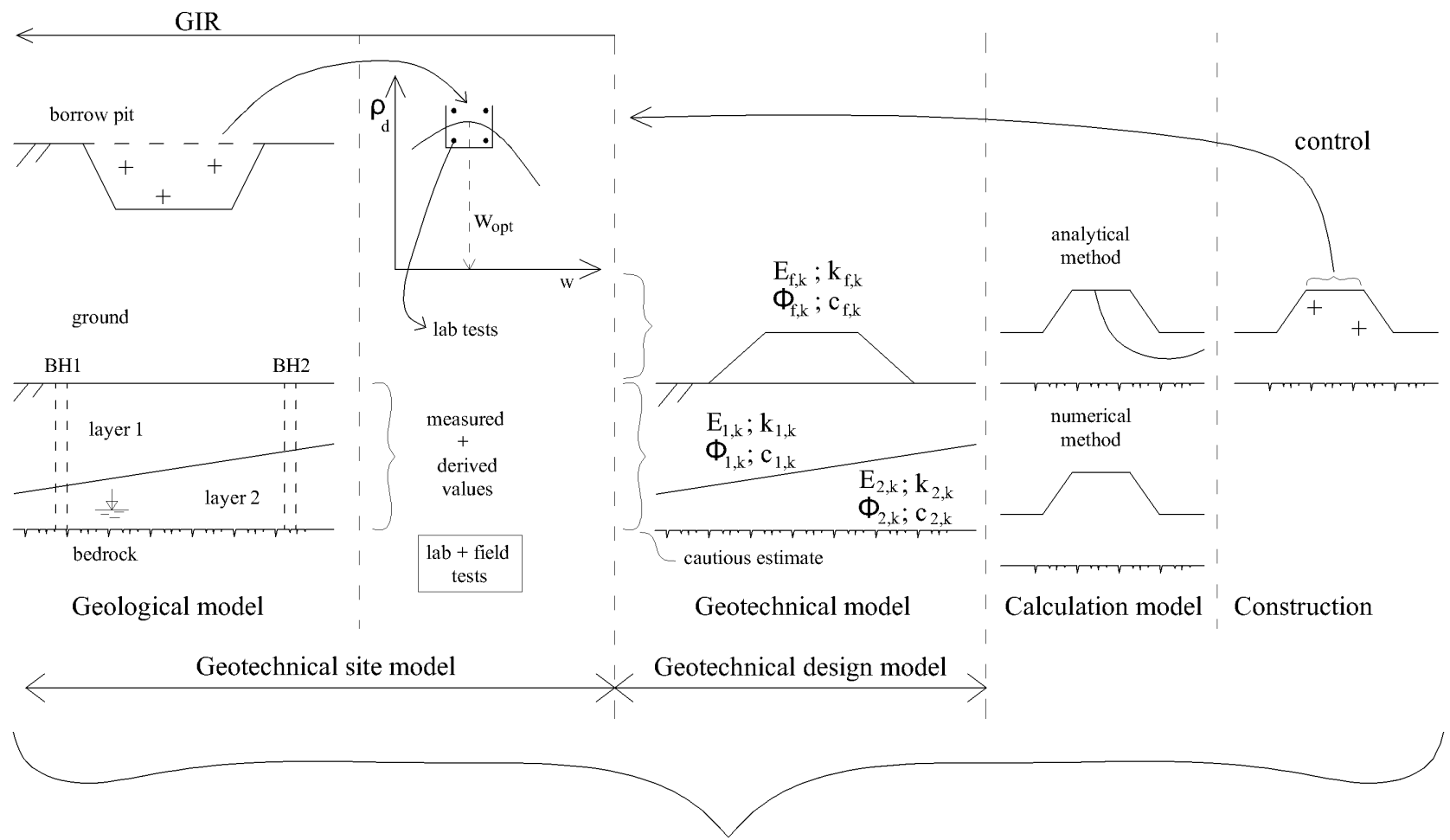

\section{Geotechnical Design Report (GDR)}

FIGURE 1. GDR scheme for earth structures.

standard tables, based on the correlation of index properties and mechanical-physical properties. Such correlation for compacted fill is e.g. used in codes for small dams, (in the CR it is e.g. code ČSN 752410 Small water reservoirs).

However for stabilized soils, firstly where the strength increase is needed, such tables can be hardly used, as there is a shortage or correlations, and therefore lab tests are needed. In this case very good cooperation between project designer and specialist on the lab tests is preferred, namely with respect to the tests performed on samples which were prepared by the nearly same way as is proposed stabilization on the site.

\section{Sensitivity of the CHARACTERISTIC VALUES DETERMINATION}

As stated already lab tests of the mechanical-physical properties are needed for structures belonging into 3 GC and 2 GC with moderate and high risk. After that the results are statistically evaluated and after subsequently they are used for the determination of the characteristic values of the geotechnical parameters. Here EC 7 defines the characteristic values as "selected as a cautious estimate of the value affecting the occurrence of the limit state". This expression should be taken very carefully, as:

- "selected" emphasizes the engineering judgement;
- "cautious estimate" emphasizes that a certain conservatism should be applied;

- "limit state" emphasizes that selected values should have close relation to the given limit state.

Nevertheless also other aspects are playing significant role during the process of selection:

- Amount of information and a degree of confidence to these information;

- Volume of ground affected by expected limit state of failure (e.g. slip surface) or an ability of the structure to transfer loads - when both aspects are connected with an ability to compensate weaker zones by stronger ones [6].

Therefore for slip surface of failure with significant length it is possible to select characteristic values closer to the average ones, while for shorter slip surface the cautious estimate will be more conservative. For all that it can be specified that the characteristic values selection is one of the most sensitive task of the project designer. Probability of verification of the selected values is very low. Quality of ground is usually not controlled, only of the fill. But even for the fill the control is going mostly via quality of compaction, whether the moisture content and dry density are falling into prescribed range. Direct tests of mechanical-physical properties are rather exceptional, e.g. permeability control for sealing system of landfills. 


\section{LABORATORY MEASUREMENT}

Laboratory tests are needed for soil stabilisation where the main aim is strength increase. Optimal content of the additives should be determined as well with mechanical-physical properties, from which the designer selects characteristic values presented some interesting results performed within her diploma theses, devoted to the additives research [7]. For given soil, characterized as clay with low plasticity (CL) she concluded, that it is material unsuitable or conditionally suitable which is also sensitive to freezing. She tested stabilization by quick lime, cement and Dorosol, and she focused on:

- Impact of lime on change of consistency limits;

- Impact of additives amount on increase of bearing capacity (controlled via CBR test);

- Impact of additives amount and time on the resistivity of stabilized soils to freezing cycles.

Follow-up diploma and $\mathrm{PhD}$ thesis are focused not only on classical soils, but also on alternative aggregates as flying ash, when different additives are tested 3]. Last attention is devoted to the combination of additives with randomly distributed short synthetic fibres. The evaluation of these tests is mostly via possibility of application of stabilized soils into road foundation - road base or sub-base layers, e.g. according to the Czech code ČSN 73 6125. Up to now lower attention is devoted to the additives application for the own fill of the earth structure. There the properties as shear parameters and deformation modulus have more informative impact, as they are needed for the solution of the limit states - ULS - ultimate limit state or SLS - serviceability limit state. The problem is very sensitive, as a stiffness increase is function of time and the designer should solve the limit states not only for short term conditions, but also for long term conditions.

\section{Conclusion}

The application of different additives for improvement of soil properties has growing tendency. From the view of lime application on fine grained soils it is necessary to distinguished between improvement from the workability view with short term effect and improvement with long term effect, when strength increase has permanent character. In the course of additives application for earth structures of transport engineering the designer should firstly specify his/her intention, whether the process of improvement is focussed on the ground and own fill or on the construction layers, as the applications (and conditions) are different. Time effect is playing important role as properties are time dependant, mostly from the view of long term bonds having decisive impact on the mechanical-physical properties. Therefore the lab tests are needed pro for demanding structures with moderate and high risk and should be focused not only on the specification of additive amount but also on the determination of soil properties reported as characteristic values. From the view of safety the designer of earth structures has to face many uncertainties with respect to the soil properties, (compared to the designer dealing with man-made construction materials) as subsequent control of the compacted soil is limited and therefore the transfer of experiences from one site to the another one is limited.

\section{ACKNOWLEDGEMENTS}

The paper was prepared with financial support from the research project TE0 120168 of the Technology Agency of the CR: CESTI - Centre of effective and sustainable transport infrastructure.

\section{REFERENCES}

[1] I. Vaníček. Significance of geotechnical investigation for geotechnical structure design. In Proceedings of $43 \mathrm{rd}$ Conference with international participation: Foundation Engineering. Brno, CGtS CICE, pp. 27-40. Brno, 2015.

[2] M. Vaníček, I. Vaníček. Earth Structures in Transport, Water and Environmental Engineering. Springer, Dordrecht, 2008.

[3] V. Mráz. Research of stabilized fly ash properties and its application for earth structures of transport engineering (in Czech). Ph.d. thesis, Czech Technical University in Prague, Faculty of Civil Engineering, 2016.

[4] H. M. Greaves. An introduction to lime stabilization. In Lime Stabilisation. Proceedings of the Seminar Held at Loughborough University, Civil ans Building Engineering Dept on 25 September 1996.

[5] J. H. Smith. Construction of lime or lime plus cement stabilized cohesive soils. In Lime Stabilisation. Proceedings of the Seminar Held at Loughborough University, Civil ans Building Engineering Dept on 25 September 1996.

[6] I. Vaníček. Jubilee volume: Andreas Anagnostopoulos 50 years of service at the National Technical University of Athens, chap. Earth Structures - sensitivity of the design to the characteristic geotechnical parameters values determination., pp. 543-552. Tsotras, 2015.

[7] Vrbová. Soil stabilization. Master's thesis, Czech Technical Universiti in Prague, Faculty of Civil Engineering, 2008. 